\title{
THE AVIFAUNA OF BISHOP AND CLERK ISLETS AND ITS RELATIONSHIP TO NEARBY MACQUARIE ISLAND
}

\author{
by Nigel Brothers \& Rod Ledingham
}

(with one table)

Brothers, N. \& Ledingham, R. 2008 (31:x): The avifauna of Bishop and Clerk islets and its relationship to nearby Macquarie Island. Papers and Proceedings of the Royal Society of Tasmania 142(1): 117-122. https://doi.org/10.26749/rstpp.142.1.117 ISSN 0080-4703. Department of Primary Industries, Water \& Environment, GPO Box 44 Hobart,Tasmania 700 1, Australia. Current address: 178 South Arm Drive, Wonga Beach, Queensland 4873, Australia (NB*); Australian Antarctic Division, Channel Highway, Kingston, Tasmania, Australia. Current address: 134 Manuka Road, Oyster Cove, Tasmania 71 50, Australia (RL). ${ }^{*}$ Author for correspondence. Email: brothersbone@yahoo.com.au

A first comprehensive survey of seabirds at Bishop and Clerk islets conducted on 23 December 1993 recorded a total of 12 species. During a three-hour-long visit by helicopter, nine species were found breeding, mostly in nests on the ground, bur also in burrows dug in shallow soil. These included the largest known colony of Black-browed Albatross, Thalassarche melanophris, in Australia. Ten bird species are now known to breed at the islets. Species accounts are given including data on morphometrics, abundance, habitats, breeding, threats, interspecific competition for space and unpublished information.

Key Words: sub-Antarctic, Bishop and Clerk islets, Macquarie Island, seabird abundance, island management.

\section{INTRODUCTION}

Bishop and Clerk islets are a tiny cluster of near-barren rocks projecting from a submarine ridge $33 \mathrm{~km}$ off the south coast of Macquarie Island in the south Pacific Ocean (54 $30^{\prime}$ S, $\left.159^{\circ} \mathrm{E}\right)$. Politically, this region is part of Tasmania, a state of Australia, therefore the status of species occurring there is subject to both Australian federal and state conservation processes. Lying within the Macquarie Island Marine Park boundary, these islets have been assigned the status of a Special Management Area (SMA) as part of the Macquarie Island Nature Reserve and World Heritage Area, recognising that, whilst the wildlife there is of scientific interest "the risks of adverse impacts outweigh almost any justification for visiting them" (Parks and Wildlife Service (PWS) 2003: 87).

The islands were visited in 1965 (MacKenzie 1968), and in 1976 (Lugg et al. 1978) prior to this declaration of importance. The timing of these earlier visits in relation to seabird breeding activity was not ideal or comprehensive. Of particular importance was to ascertain how a number of petrel species were managing to maintain breeding populations on rock stacks immediately adjacent to Macquarie Island's coastline, despite apparent successive total breeding failures (Brothers 1984). Were the Macquarie Island populations being supplemented by immigration from elsewhere and were Bishop and Clerk islets the likely source as inferred by Lugg et al. (1978)? Alternately, were there other, as yet unknown, processes enabling these petrel colonies to persist? The implications of immigration from offshore populations for petrel population recovery following vertebrate pest management on Macquarie Island (Copson 1995) were considered to be of potential significance. Because of this and also to ensure efforts to update and review the regional status of albatross (Gales 1993, 1998) included information on numbers known to breed on Bishop and Clerk islets, a visit was planned. Attempts were unsuccessful in 1982 and 1988, but a visit was successfully accomplished in 1993. This paper provides the only comprehensive avifauna account for the locality from what may be the last visit permitted.

\section{MATERIALS AND METHODS}

One helicopter, accompanied by the Antarctic resupply vessel MV Icebird was used to deploy a field party onto Bishop Islet the largest islet in the group and the only one habitable to wildlife for breeding, on 23 December 1993. To maximise the benefit of what could only be a brief three-hour (1230-1530 hrs) visit, a total of seven personnel participated in various work including studies on invertebrates (Davies et al. (1997)), seals (Goldsworthy unpubl. data) and Macquarie Shag, Leucocarbo atriceps purpurascens Brandt, 1837, diet (Kato unpubl. data) as well as this census of birds.

All habitats were thoroughly searched and direct counts made of bird species abundance and their breeding status noted. The relative importance of the seabird populations inhabiting Bishop and Clerk islets was then assessed against the most appropriate data available for nearby Macquarie Island.

Whilst at the time of this visit no access restrictions specific to the locality applied, as they do today, specific quarantine precautions were taken to preclude the inadvertent or uncontained transfer of organisms between Macquarie and Bishop and Clerk islets.

\section{SPECIES ACCOUNTS}

Of the 12 species of seabirds observed, nine were confirmed breeding, five of these being first records for this locality and two being new records for the Macquarie Island region or not known as species breeding in Australia (excluding the Australian external territories of Heard and McDonnell islands). One species, which had previously been recorded breeding here, was present but not breeding, with the result that ten species are now known to breed at this locality. 


\section{Wilsons Storm-Petrel, Oceanites oceanicus (Kuhl, 1820)}

Three burrows, two containing an adult and one egg, and one containing two adults with no egg were found in the same vicinity and habitat as the diving-petrels. Prior to the destruction caused by Black Rats, Rattus rattus (Linnaeus, 1758), European Rabbits, Oryctolagus cuniculus (Linnaeus, 1758), Feral Cats, Felis catus Linnaeus, 1758 and Weka, Gallirallus australis (Sparrman, 1786), it is likely that this species was abundant on Macquarie Island itself. Its presence on Bishop Islet is the first record of the species in this region and a new breeding record for Australia (not including its external territories of Heard and McDonnell Islands plus those in the Australian Antarctic Territory (Marchant \& Higgins 1990)).

Breeding by this species on Bishop Islet is added confirmation that rats do not exist here despite perhaps having had at least one opportunity from shipwreck to do so (Cumpston 1968). Regardless, evidence from other islets adjacent to Macquarie Island suggests that even if rats did come ashore at any time on Bishop Islet they could not survive long-term under the environmental conditions here (Brothers \& Bone 2008).

One egg measured $32.9 \times 24.1 \mathrm{~mm}$. Measurements from three adult birds are given in table 1 .

\section{Black-browed Albatross, Thalassarche melanophris (Temminck, 1828)}

A total of 141 nests was recorded. Of these, 78 contained a chick, 13 an egg, ten had egg-shell fragments and 40 were empty. Despite a general lack of nest-building material all nests were well-formed suggesting that they had all been constructed and occupied that season. Unoccupied nests are soon destroyed by neighbouring birds, particularly at such localities where construction material is scarce.

Each nest built represents a potential breeding pair and, although it is likely that an egg was not actually laid in every nest (at Macquarie Island colony $83 \%$ of nests have eggs laid in them (DPIWE unpubl. data)), 140 breeding pairs is considered a realistic population estimate. This estimate is the same as that assigned to this population by Garnett \& Crowley (2000).

The data indicate a reduced breeding success of about 35\% at this early stage of the breeding cycle. This is consistent with observations at the Macquarie Island colony (DPIWE unpubl. data).

TABLE 1

Standard measurements (in $\mathrm{mm}$ ) of three adult Wilson's Storm-Petrels on Bishop Islet

\begin{tabular}{lrcc}
\hline & Bird 1 & Bird 2 & Bird 3 \\
\hline Culmen & 12.9 & 12.8 & 14.0 \\
Bill width at base & 6.9 & 6.9 & 6.8 \\
Tarsus & 35.8 & 33.7 & 33.5 \\
Mid toe + claw & 29.9 & 26.8 & 28.1 \\
Mid claw & 4.5 & 4.5 & 5.4 \\
Wing & 159 & 148 & 149 \\
Tail & 65 & 57 & 60.5 \\
\hline
\end{tabular}

Nesting habitat differences occur between the two localities and could account for any differences in breeding success. Nest site exposure to adverse weather conditions at Bishop Islet, the availability of an entirely tock substrate with limited nest-building material together with a high proportion of sites being relatively difficult for adults to access may account for differences in breeding success between the two sites.

Interchange between sites is supported by the observation that one 11-year-old Macquarie Island bird banded as a fledgling was present in the Bishop Islet colony. Given that the bird has never been recorded back in the Macquarie Island colony over the 20-year period, despite comprehensive searches (DPIWE unpubl.) it is suggested that it may have permanently established in the Bishop Islet colony. Although fledgling survival seems to be significantly higher at Macquarie Island compared to populations elsewhere (Terauds et al. 2005), recruitment into the Bishop Islet colony cannot be discounted. The annual incidence of unbanded birds being encountered in the Macquarie Island population (which consists entirely of banded birds), is less than 5\% (Terauds pers. comm.) suggesting immigration from Bishop Islet (where no birds have been banded) to be a rare event.

With as few as 45 breeding pairs now at just one site on Macquarie Island (PWS 2003), the colony on Bishop Islet has been recognised as significant for the region since MacKenzie's first observations (1965). The timing of the two previous visits to this site together with uncertainties about the completeness of the counts undertaken, precludes comparison or comment on population trends.

Emigration from the Macquarie colony is likely to be influenced by the fact that the greatest numbers of individuals present in the region with which to interact socially at sea will most likely be from the Bishop Islet colony. The aggregation of birds created by fishing vessel activity, especially in the vicinity of the island, is likely to increase the potential for this to occur.

Other potential threats to the stability of the Bishop Islet colony include the observation that both Rockhopper and Royal penguins access the Bishop Islet colony, breeding adjacent to the albatross in similar habitat. In the same vicinity, penguins appear to occupy the more suitable sites, suggesting dominance, which could have a negative impact on albatross population size should penguins increase in abundance. As it is, this occupation of more suitable nesting habitat by the penguins might be lowering albatross breeding success. Direct nest site competition such as this is not a factor influencing performance at the Macquaric Island Black-browed Albatross colony.

\section{Salvin's Albatross, Thalassarche cauta salvini} (Rothschild, 1893)

One individual of adult appearance was present amongst nesting Black-browed Albatross. Whilst it gave no indication of having an association with any specific site or nest, the possibility that this species does nest here cannot be discounted. A new colony of this species has recently become established in the Crozet Archipelago (Jouventin 1990) and such an establishment on Bishop Islet could disrupt or displace less aggressive Black-browed Albatross. There are no previous records of Salvin's Albatross ashore but small numbers are sighted regularly at sea in the Macquarie Island region accompanying a fishing vessel (Australian Fisheries Management Authority (AFMA), unpubl. fisheries observer 
data). It is not uncommon however for an individual albatross to frequent the breeding colonies of a different albatross species but never to breed at that locality.

\section{Fairy Prion, Pachyptila turtur (Kuhl, 1820)}

MacKenzie (1968) and Lugg et al. (1978) hypothesised that Fairy Prions could nest in rock crevices on Bishop Islet. This hypothesis was confirmed with birds found occupying two cliff crevices within $20 \mathrm{~m}$ of the summit. Three birds were incubating eggs and there were another three unattended eggs. Both crevices provided very limited nesting opportunities and whilst one or two other suitable crevices may have been overlooked, this locality can support only very small numbers of this species. The occupied crevices here are reminiscent of the other sites adjacent to Macquarie Island at which this species nests (Brothers 1984).

Despite being small, the Bishop Islet colony is significant for the region because only small numbers (about 40 pairs) are known to occur at two localities elsewhere and, unlike at Bishop Islet, all are vulnerable to the predatory Black Rat.

\section{Common Diving-Petrel, Pelecanoides urinatrix (J.F. Gmelin, 1789)}

One burrow, containing a well-developed chick was found beneath Colobanthus cushions adjacent to the summit of Bishop Islet. It is estimated that this chick would have originated from an egg laid in late September, a timetable consistent for the species. No other burrows of this species were found to occur here. As with the Fairy Prion, this species has been all but exterminated on Macquarie Island by introduced predators and survives at only one, or possibly two, other offshore sites adjacent to Macquarie Island but in very low numbers (Brothers 1984, Brothers \& Bone 2008).

\section{South Georgian Diving-Petrel, Pelecanoides georgicus Murphy \& Harper, 1916}

Three burrows found adjacent to the summit of Bishop Islet, beneath Colobanthus cushions, each contained an adult bird incubating an egg. Whilst Murphy \& Harper (1921) speculated that this species breeds in the Macquarie Island region this is the first confirmation of this and also constitutes a new breeding record of the species for Australia, not including the external territories of Heard and McDonald Islands (Marchant \& Higgins 1990).

\section{Gentoo Penguin, Pygoscelis papua (J.R. Forster, 1781)}

No Gentoo Penguins were found breeding on Bishop or Clerk islets, but 149 birds were recorded ashore with eight Royal Penguins (Eudyptes schlegeli) on a smaller islet just to the east of Bishop Islet. This unnamed islet offered easy access for these species. Given that birds forage daily from Macquarie Island (Hindell 1989), it is likely that these sites are used regularly.

It has been hypothesised that Gentoo Penguins compete directly for food resources with Macquarie Shags (Brothers 1985), so maximising competition for these resources at this distant locality might be assisted by having access to rest ashore as an option instead of swimming $33 \mathrm{~km}$ directly back to Macquarie Island.
This is uncharacteristic behaviour, but the data presented here, indicate that such use of sites does occur.

Although Gentoo Penguins, together with two other penguin species, the Rockhopper Penguin Eudyptes chrysocome and the Royal Penguin Eudyptes schlegeli could access Bishop Islet itself, typical nesting requirements of the 3800 pairs on Macquarie Island (Robinson in PWS 2003) are lacking. These observations together with this more appropriately-timed visit to ascertain breeding timetables, removes earlier uncertainty (Lugg et al. 1978) about breeding status here.

\section{Rockhopper Penguin, Eudyptes chrysocome (J.R. Forster, 1781)}

Rockhopper Penguins occupied 166 nest sites in typical rocky habitat adjacent to, and interspersed with, Royal Penguins.

Although previously known to breed here (Lugg et al. 1978), this is the only reliable population estimate.

Approximately 100000 pairs of Rockhopper Penguins breed on Macquarie Island (Rounsevell \& Brothers 1984) and similar interactions with Royal Penguins are encountered there.

\section{Royal Penguin, Eudyptes schlegeli Finsch, 1876}

Nesting on Bishop Islet was recorded with 457 occupied nests encountered. Eight of these had one egg and the rest contained chicks. A vast 850000 pairs breed on Macquarie Island (Copson \& Rounsevell 1987). Although only eight individuals were ashore with Gentoo Penguins on the small islet to the east of Bishop Islet the earlier accounts of Mackenzie (1968) indicate high usage of this site at times but not for breeding purposes.

\section{Macquarie Shag, Leucocarbo atriceps purpurascens Brandt, 1837}

Three localities at which this species nest were found on Bishop Islet with a total of 164 nests, 148 at the main site to the east, 15 in the southeast and a single one in the northwest amongst nesting Black-browed Albatross.

There were 59 empty nests, four with one egg, nine with two eggs and four with three eggs plus 22 with one chick, 59 with two chicks, three with three chicks and two with one egg and two chicks and one with two chicks alive, one dead. Because nest site retention by adults in this species is very strong and persistent (Brothers 1985), the above count is considered an accurate indication of total breeding pairs here.

If nest content at this time of year and in this season is any indication (in particular the proportion of nests that were either empty or contained only one chick) productivity appears to be less than at a Macquarie Island colony studied (Brothers 1985). Explanations for this may include food shortages, a factor believed to influence breeding success of this species (Brothers 1985) even where birds have access to areas that remain suitable for foraging during inclement weather. In addition to limited food availability, the necessity of reliance upon only seaweed for nest building here may also diminish breeding success. Unlike nests on Macquarie Island that are all constructed from readily available terrestrial plant species (Brothers 1985) with only the odd shore-cast seaweed fragment incorporated, Bishop Islet nests are constructed 
exclusively of seaweed collected by the birds at sea. The only terrestrial plant, Colobanthus muscoides Hook.f., on Bishop Islet is not sufficiently abundant to sustain its use for nest building nor is it really suitable for this purpose. A shortage of nest material will exacerbate the King Shag's destructive habit of robbing nest material and would have a significant impact on the breeding success of this colony.

MacKenzie (1968) considered that the Bishop Islet colony could act as a reservoir for maintaining shag numbers at Macquarie Island colonies where nest sites of lower elevation are more susceptible to storms. Whilst it is true that Macquarie Island colonies can be susceptible to storm flooding (Brothers 1985) it is most likely that the Bishop Islet portion of the population was overestimated and factors affecting productivity on Bishop Islet had not been considered by MacKenzie in reaching this conclusion. Furthermore, given the colony tenacity evident in Macquarie Island colonies (Brothers 1985), it is unlikely that Bishop Islet breeding birds and their offspring would enter the Macquarie Island breeding population.

Variation in annual individual colony counts on Macquarie Island does suggest, however, some movement between colonies. To illustrate this point, counts at the largest of all colonies were 311 nests (in 1975), 332 (1976), 348 (1977), 343 (1988), 364 (1993) and 417 (1999). The next largest colony varied from 51 nests to 132 nests over this period. Whilst nesting sites are generally used every year, some colonies can be abandoned for a season or more (Brothers 1985). This perhaps accounts for much of the colony nest count fluctuations. Regardless, the tendency for large colonies to remain large and, if not at the same exact site, always in the same region supports the belief that similar numbers are likely to nest at Bishop Islet each year.

Limited benthic foraging areas, upon which this species appears to be dependent (Brothers 1985), exist in the vicinity of Bishop Islet. Prevailing weather conditions and distance largely prevent Bishop Islet birds and Macquarie Island birds from exploiting each another's foraging grounds. Foraging area is also likely to determine population size on Bishop Islet.

Given the fluctuations in nest counts experienced on Macquarie Island over the years, the validity of using a single count from Bishop Islet to provide a total species population estimate should be treated with caution. With 164 nests, the Bishop Islet colony is significant, being similar in size to the second largest colony on Macquarie Island but three or more times larger than all others.

A previous estimate of population size of King Shags for the Macquarie Island area of 760 pairs (Brothers 1985 ) assigned only 100 pairs to the Bishop Islet colony. Combining the one accurate count of 164 nests with the most recent Macquarie Island census in the 1999/2000 breeding season indicates a total population size for the species of 1047 pairs.

\section{Great Skua, Stercorarius antarctica lonnbergi (Matthews, 1912)}

Two adult birds and an empty nest were encountered which is consistent with observation made of this species during previous visits. There are approximately 200 pairs of this species breeding on Macquarie Island (Skira 1984).

\section{Kelp Gull, Larus dominicanus Lichtenstein, 1823}

Although six adults and 13 juveniles were present, no evidence of breeding was found. Confirmation that this species does breed here was made by MacKenzie (1968) and it is considered likely that at least one pair does so each year.

At nesting sites of this species on Macquarie Island a breeding pair is invariably assisted in site defence by several other adult birds as well as juveniles. Therefore the numbers observed on Bishop Islet do not necessarily indicate that more than one pair may breed. The total population for the Macquarie Island region is 127 breeding pairs (Brothers \& Bone 2008).

\section{DISCUSSION}

Although four species of burrow-nesting petrels were found nesting on Bishop Islet for the first time, absence of Blue Petrels, Halobaena caerulea (J.F. Gmelin, 1879), was unexpected. Because suitable habitat is scarce it is not possible for even small numbers of this species or for larger populations of the other species actually found, to exist here. Not only does habitat availability limit abundance, its characteristics also dictate that only the smaller burrow-nesting petrel species can occupy this site.

The species that were found have provided further evidence of which species may have once constituted the burrownesting avifauna of Macquarie Island prior to extermination by vertebrate pests. This may also be indicative of species that are expected to re-occupy Macquarie Island after completion of the Integrated Vertebrate Pest Management Plan (Copson 2004). A notable exception to this hypothesis is the absence of Cape Petrels, Daption capense (Latham, 1758), on Bishop Islet despite suitable nesting habitat, which suggests this species was not eliminated from Macquarie Island by introduced pests. Cape Petrels however, do frequent Anchor Rock, an apparently less suitable site adjacent to Macquarie Island (Lugg et al. 1978, Brothers \& Bone 2008) so could exploit more favourable nesting conditions, should these be created.

There are insufficient numbers of all species on Bishop Islet to affect the existing conservation status that has been assigned to them by Garnett \& Crowley (2000).

\section{ACKNOWLEDGEMENTS}

For their participation in the collection of information during the visit to Bishop Islet we thank Noel Carmichael, Kendi Davies, Simon Goldsworthy, Akito Kato and Terry Reid. The Australian Antarctic Division supplied the logistics for the visit. Gerry Findly flew the helicopter. Kerrin Jeffrey and Catherine Bone assisted with preparation of the manuscript. Alex Terauds (DPIWE) and Bob Stanley (AFMA) provided useful unpublished information. In particular, we thank Peter Mooney, Parks and Wildlife Service General Manager, Department of Tourism, Arts and the Environment, Tasmania. For his contribution towards preparation of the manuscript we thank David Rounsevell. 


\section{REFERENCES}

Brothers, N.P. 1984: Breeding, distribution and sratus of burrownesting petrels at Macquarie Island. Australian Wildlife Research 11: 113-31.

Brothers, N.P. 1985: Breeding biology, dier and morphometrics of the King Shag, Phalacrocorax albiventer purpurascens, at Macquarie Island. Australian Wildlife Research 12: $81-94$.

Brothers, N. \& Bone, C. 2008: The response of burrow-nesting petrels and other vulnerable bird species to vertebrate pest management and climate change on sub-Antarccic Macquarie Island. Papers and Proceedings of the Royat Society of Tasmania 142(1): 123--148.

Copson, G.R. \& Rounsevell, D.E. 1987: The abundance of Royal Penguins (Eudyptes schlegeli Finsch) breeding at Macquarie Island. ANARE Research Notes 41: iii, iv, 1-11.

Copson, G.R. 1995: An integrated vertebrate pest strategy for subantarctic Macquarie Island. In Proceedings of the $10^{\text {th }}$ Vertebrate Pest Control Conference, Hobart. Department of Primary Industry and Forestry, Hobart, May 1995: 29-33.

Copson, G.R. 2004: Draft Plan for the eradication of rabbits and rodents on subantarctic Macquarie Island. Report for National Heritage Trust, Department of Primary Industries, Water and Environment. Hobart: 76 pp.

Cumpston, J.S. 1968: Macquarie Island. ANARE Scientific Reports, Series A(1), Antarctic Division: 380 pp.

Davies, K., Greenslade, P. \& Melbourne, B. 1997: The invertebrates of sub-Antarctic Bishop Island. Polar Biology 17: 455-458.

Gales, R. 1993: Co-operative Mechanisms for the Conservation of Albatross. Report for Australian Nature Conservation Agency, Canberra: $132 \mathrm{pp}$.

Gales, R. 1998: Albatross populations: starus and threats. In Robertson, G. \& Gales, R. (eds): Albatross Biology and Conservation. Surrey Beatty, Chipping Norton: 20-45.
Garnett, S.T. \& Crowley, M. 2000: The Action Plan for Australian Birds 2000. Environment Australia, Canberra: 673 pp.

Hindell, M.A. 1989: The dict of Gentoo Penguins Pygoscelis papud at Macquarie Island. Emu 88: 219-226.

Jouventin, P. 1990: Shy Albatrosses Diomeded cautd salvini breeding on Penguin Island, Crozet Archipelago, Indian Ocean. Ibis 132: 126-127.

Lugg, D.J., Johnstone, G.W. \& Griffin, B.J. 1978: The outlying islands of Macquarie Island. The Geographical Journal 144(2): 277-287.

MacKenzie, D. 1968: The birds and seals of the Bishop and Clerk islets, Macquarie Island. Emu 67(4): 241-245.

Marchant, S. \& Higgins, P.J. 1990: Handbook of Australian New Zealand and Antarctic Birds. Vol. 1. Oxford University Press, Melbourne: $1440 \mathrm{pp}$.

Murphy, R.C. \& Harper, F. 1921: A review of the Diving Petrels. Bulletin American Museum National History 44(17): 495-554.

Parks and Wildlife Service, 2003: Macquarie Island Nature Reserve and World Heritage Area Management Plan. Parks and Wildlife Service, Department of Tourism, Arts and the Environment. Hobart: 1-176.

Rounsevell, D.E. \& Brothers, N.P. 1984: The status and conservation of seabirds at Macquarie Island. In Croxall, J.P., Evers, P.G.H. \& Schreiber, R.W. (eds): Status and Conservation of the World's Seabirds. ICBP Cambridge: 587-592.

Skira, I.J. 1984: Breeding distribution of the Brown Skua on Macquarie Island. Emu 84(4): 248-249.

Terauds, A., Gales, R. \& Alderman, R. 2005: Trends numbers and survival of Blackbrowed (Thalassarche melanophrys) and Grey-headed (T. chrysostoma) albatrosses breeding on Macquarie Island. Emu 105(3): 159-167.

(accepted 5 August 2008) 